\title{
Analysis of Outcome of Intraplueral Streptokinase in Pediatric Empyema Thoracis even in Advanced Stages: A Prospective Study
}

\author{
Kallol Bose, ${ }^{1,}{ }^{*}$ Sudip Saha, ${ }^{2}$ Dhrubojyoti Mridha, ${ }^{1}$ Kallol Das, ${ }^{3}$ Piyasi Mondal, ${ }^{3}$ and Ira Das ${ }^{3}$ \\ ${ }_{1}^{1}$ Assistant Professor, Pediatrics Chittaranjan Seva Sadan Hospital, Kolkata, India \\ ${ }^{2}$ Associate Professor, Pediatrics Chittaranjan Seva Sadan Hospital, Kolkata, India \\ 3 RMO cum CT, Pediatrics Chittaranjan Seva Sadan Hospital, Kolkata, India \\ *Corresponding author: Kallol Bose, Assistant Professor, Pediatrics Chittaranjan Seva Sadan Hospital, Kolkata, India. Tel: +91-9836653608, E-mail: subhosrisaha@gmail.com
}

Received: June 27, 2015; Revised: July 13, 2015; Accepted: August 16, 2015

\begin{abstract}
Background:Empyema thoracis in children causes significant morbidity. Standard treatment of Empyema thoracis includes tube drainage and antibiotics. But the tube drainage often fails. Intrapleural Streptokinase has been used in empyema thoracis with good success rate. Objectives: We evaluated the efficacy of intra-pleural Streptokinase in management of empyema thoracis even in advanced stages. Patients and Methods: A total of 28 patients with empyema thoracis requiring intercostal tube drainage aged zero to twelve years were included in the study who were admitted in Pediatric intensive care unit. 15,000 units/kg of Streptokinase was instilled into the pleural cavity. Response was assessed by clinical outcome, after unclamping and subsequent chest radiography and serial chest ultrasounds.

Results: Streptokinase enhanced drainage in all patients with complete resolution of empyema thoracis in 26 patients. Two patients were referred for surgery. Only 7.2\% required surgery. Streptokinase was equally effective if started before or after seven days.

Conclusions: Intrapleural Streptokinase is the preferred treatment for treating pediatric empyema thoracis even in advanced stages and can avoid surgery.

Keywords: Empyema Thoracis; Pediatrics; Streptokinase
\end{abstract}

\section{Background}

Empyema thoracis is an uncommon complication of childhood pneumonia and general pediatricians may only see a few cases in their career (1). Although mortality rates in pediatric empyema thoracis are very low, empyema thoracis causes significant morbidity including substantial health care costs and burden of care. Childhood empyema thoracis occurs in 0.7 - 3.3 per 100,000 population worldwide $(1,2)$. Recent studies in countries such as USA, Canada, Spain, France, Scotland and England have suggested that the number of cases of childhood empyema thoracis have been increasing. The cause for this is unclear but a number of reasons have been postulated, including a decrease in antibiotic use in primary care. Another suggestion has been that the rise is related to the introduction of the 7-valent pneumococcal vaccine ( $7 \mathrm{v}$ PVC) into national immunization programs which has led to an increase in invasive pneumococcal empyema thoracis disease caused by nonvaccine serotypes (3-14). This view is in contrast to a number of studies throughout the world, including Australia, which has shown an increase in the prevalence of empyema thoracis prior to the introduction of the $7 \mathrm{v} \operatorname{PVC}(1,15,16)$. Many treatment options are available, however due to a lack of quality research there is limited high grade evidence to direct best standards of care. It is unclear whether optimal management is closed tube drainage or video assisted thoraco-scopic surgery (VATS) followed by chest tube drainage (17). In our country VATS is not widely available, so on failure of medical treatment, open decortication is often needed. As per newer guidelines isolated intercostal tube drainage without fibrinolytics preferably be avoided (18).

\section{Objectives}

In our study we wanted to show the role of intrapleural streptokinase in an attempt to reduce the need for surgery which is costly and cumbersome. We want to reveal the age and sex distribution of empyema thoracis patients, organism pattern, relation of outcome to the different time of initiation of intrapleural streptokinase and difference in ultimate outcome in terms of clinical and radiological resolution.

\section{Patients and Methods}

A prospective study was done on children aged 0 to 12 years with features of empyema thoracis attended in our tertiary care hospital Pediatric Intensive Care Unit in the time frame of December 2012 to November 2014. 32 cases were taken but 4 of them left out without follow 
Bose Ket al.

up or insignificant fluid collection. Empyema thoracis was confirmed clinically, by chest x-ray and ultrasonography (USG), laboratory investigations: organism on gram staining, $\mathrm{pH}<7.2$, cell count $>10,000 / \mu \mathrm{L}$. Decision for insertion of chest tube was taken depending upon clinical condition of patients and radiologic and laboratory evidence. All moderate to severe collections were selected and also mild collections with significant respiratory distress or deteriorating clinically and/or radiologically with conservative treatment. Fluid was aspirated in all cases and examined by naked eye and was sent for routine and microscopic examination (protein, lactic dehydrogenase, glucose, total cells, differential count, cytological examination and $\mathrm{pH}$ ) along with culture sensitivity. Consent was taken from legal guardians in preformed proforma after proper counselling and approval was taken from institutional Ethical committee prior to study and publication. Data were collected in preformed proforma including age, sex, onset of symptoms in three different age groups ( $<12$ months, 13 - 24 months, $>24$ months).

Chest tube was inserted with water seal drainage and intrapleural streptokinase in a dose of 15,000 unit/kg started by syringe pump (17). Duration of infusion was one hour and clamping was done for four hours and then free drainage was allowed. Duration of infusion varied from three to twelve days depending on regular clinical check-up, regular ultrasound assessment and chest $\mathrm{x}$-ray, the latter was done every three days until resolution occurred. Intravenous antibiotics and supportive management were continued as per our institutional protocol. Chest drain was removed on clinical and radiological improvement when less than one $\mathrm{mL} /$ $\mathrm{kg}$ per day of fluid was drained. After removal of chest drain repeat x-ray was done immediately and after one month, three months and six months. In two patients re-insertion of chest tube was needed with prolongation of intrapleural streptokinase administration. Two cases not responding clinically and radiologically were referred to cardiovascular surgery department. Response to treatment was defined as reduction of respiratory distress, improvement of clinical finding in the form of better air entry and improvement of x-ray and ultrasonography finding. Resolution was defined as complete or near complete disappearance of opacity on chest x-ray and insignificant fluid in pleural space on USG. Data were tabulated and statistical analyses were performed with help of Epi Info (TM) 3.5.3. EPI INFO is a trademark of the Center for Disease Control and Prevention (CDC). Using this software, basic cross-tabulation, inferences and associations were performed.

\section{Results}

In our study we divided twenty eight patients in three age groups $<12$ months: 13 - 24 months, $>24$ months. $32.1 \%$ $(n=8)$ were in the first group, 53.6\% $(n=16)$ in the second and $14.3 \%(n=4)$ in the third. Among the study population
53.6\% $(n=16)$ were female and $43.6 \%(n=12)$ male. $71.4 \%$ cases showed no growth on pleural fluid culture. Staphylococcus aureus was detected in majority (17.9\%) of cases, Pnemococcus and Hemophilus influenzae were detected in $7.1 \%$ and $3.6 \%$ respectively. In the age group of $<12$ months $25 \%$ of cases, and in 13 to 24 months age $37.5 \%$ of cases showed growth in pleural fluid culture while in all patients above 24 months fluid was sterile. In this study $32.1 \%$ of patients $(\mathrm{n}=9)$ were started intrapleural streptokinase within 7 days of symptom onset (early starter) and $67.9 \%(n=19)$ received streptokinase after 7 days of onset of symptoms (late starter). This value is statistically significant $(\mathrm{z}=2.67$, $\mathrm{P}=0.007)$. Two of the early starters and sixteen of late starters had multiloculated empyema thoracis on USG. Out of 28 patients only two (7.2\%) required surgery, and 26 patients responded to intrapleural streptokinase along with intravenous antibiotics which is statistically significant ( $\mathrm{z}$ $=6.41, \mathrm{P}=0$ ). Surgery was needed in $<12$ month and 13 to 24 month age groups-one for each group. In each age group intrapleural streptokinase is significantly successful in reducing the need for surgery. After receiving intrapleural streptokinase along with intravenous antibiotics the need for surgery is reduced to minimal and statistically insignificant $(P=1)$, whereas success of medical treatment is statistically significant $(\mathrm{P}=0.003)$. Streptokinase benefited both in early and late starters and there was no statistically significant difference in outcome regarding benefit of streptokinase among the early and late starters $\left(\chi^{2}=1.02 ; \mathrm{P}=0.312\right)$. $44.4 \%$ of patients in the age group of $<12$ months received streptokinase before 7 days of onset of symptoms, $26.7 \%$ and $25 \%$ received the same before 7 days in 13 to 24 months and $>24$ months age groups. Two patients who required decortication surgery were positive for Pnemococcus and Staphylococcus aureus in pleural fluid culture. All patients were followed up for six months as per protocol and all showed resolution on chest x-ray. During our study no major complication except bleeding from tube insertion site in three patients needing pressure and stitch occurred.

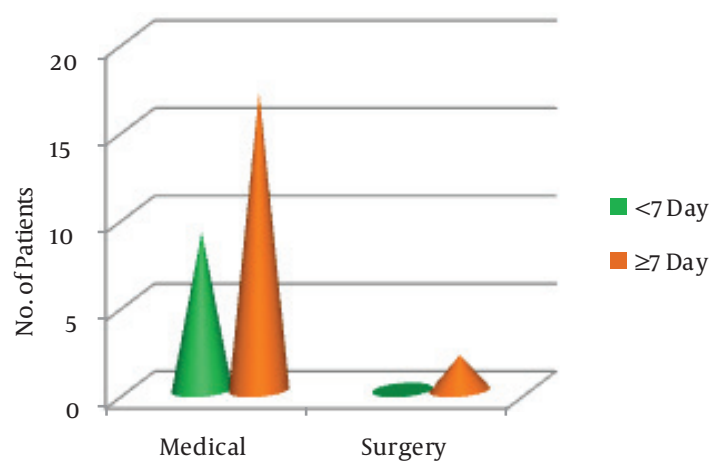

Figure 1. No. of Patients Requiring Medical and Surgical in Early and Late Starter 
Bose Ket al.

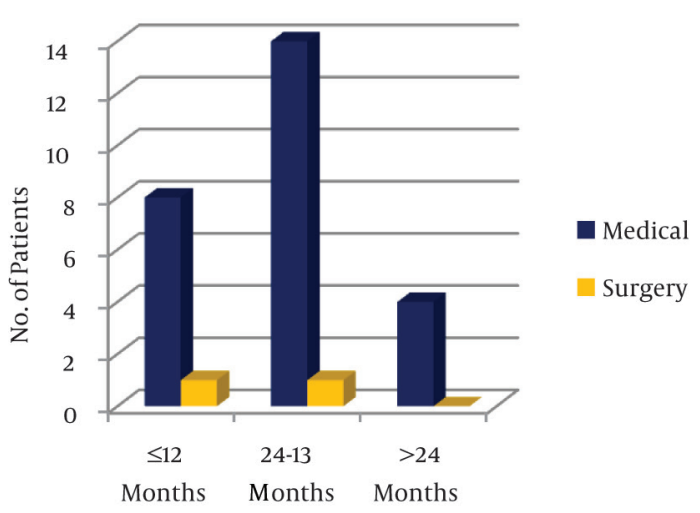

Figure 2. Age Wise Distribution of Patients Managed Medically or Surgically

\section{Discussion}

Empyema thoracis is an accumulation of pus in pleural space. It is most often associated with pneumonia due to Streptococcus pneumoniae, although Staphylococcus aureus is most common in developing nations and Asia (17). Haemophilus influenzae, group A Streptococcus, gram negative organisms, tuberculosis, fungi, malignancy and trauma are other causes. Empyema thoracis consists of three stages-exudative phase (fibrinous exudates forms on pleural surfaces), fibrinopurulent phase (fibrinous septa form, causing lobulation and thickening of parietal pleura), and organization phase. Though empyema thoracis in children caries very little (20\%) mortality as compared to adults, it causes lots of morbidity and complications. If pus is not drained in second phase it may dissect through pleura into lung parenchyma leading to bronchopleural fistula (BPF), pyopneumothorax, in abdominal cavity or through chest wal 1 (empyaema necessitates). If organized lung may collapse and become surrounded by thick inelastic peel. Option for drainage is controversial. Some experts are in favor of VATS followed by chest tube drainage, some experts opine in favor of closed tube drainage with or without fibrinolytics, some think of early decortication (19). We wanted to reveal the role of intrapleural streptokinase in management of pediatric empyema thoracis and also its role in reducing the number of surgery. Often cases are referred to the tertiary care hospital after several days of onset of symptoms. We wanted to reveal the role of streptokinase in late (> 7 days) starters also. In this study statistically significant number of cases was referred late (9 vs. 19). One of our patients was started streptokinase even on 23rd day of illness and showed complete resolution. Decortication was needed in two patients only both of them were started streptokinase after 7 days as they were referred late but rest 17 cases in this group were successfully managed by medical treatment. All 9 patients who were administered streptokinase before 7 days needed no surgery. Only 2 patients out of 26 (7.2\%) needed decortication. Failure rate in our study is less than in other studies. In other studies it is $19.44 \%, 8.1 \%(20,21)$. Statistical significance of medical management over surgery has been demonstrated in this study. Similar result was demonstrated by 22 . Sonnappa et al. (22), Thomson et al. (23), Khan et al. (24). A recent meta-analysis of 10 trials (25) reported that intrapleural fibrinolytics reduced the need for surgery and duration of hospitalization. Some are still favoring surgery. In some studies VATS or surgery was preferred choice in late ( $>7$ days) phase but we are showing that medical management can reduce surgery even in late phase. Ekingen et al. (26) showed success of medical management of $96 \%$ in early phase and $72.2 \%$ in late phase. So we suggest that up to stage 2 (fibrinous phase) streptokinase must be tried as it is safe and most often reduces the cost and hazards of surgery. Although in our study we did not face any major complication related to insertion of intercostal tube or administration of streptokinase, coagulopathy, intra-pleural hemorrhage, hemothorax, anemia and shock were rarely reported (27).

\section{References}

1. Strachan R, Jaffe A, Australian Research Network in E. Assessment of the burden of paediatric empyema in Australia. J Paediatr Child Health. 2009;45(7-8):431-6.

2. Jaffe A, Balfour-Lynn IM. Management of empyema in children. Pediatr Pulmonol. 2005;40(2):148-56.

3. Bekri H, Cohen R, Varon E, Madhi F, Gire R, Guillot F, et al. [Streptococcus pneumoniae serotypes involved in children with pleural empyemas in France]. Arch Pediatr. 2007;14(3):239-43.

4. Byington CL, Spencer LY, Johnson TA, Pavia AT, Allen D, Mason EO, et al. An epidemiological investigation of a sustained high rate of pediatric parapneumonic empyema: risk factors and microbiological associations. Clin Infect Dis. 2002;34(4):434-40.

5. Byington CL, Korgenski K, Daly J, Ampofo K, Pavia A, Mason EO. Impact of the pneumococcal conjugate vaccine on pneumococcal parapneumonic empyema. Pediatr Infect Dis J. 2006;25(3):250-4.

6. Calbo E, Garau J. Invasive pneumococcal disease in children: changing serotypes and clinical expression of disease. Clin Infect Dis. 2005;41(12):1821-2.

7. Calbo E, Diaz A, Canadell E, Fabrega J, Uriz S, Xercavins M, et al. Invasive pneumococcal disease among children in a health district of Barcelona: early impact of pneumococcal conjugate vaccine. Clin Microbiol Infect. 2006;12(9):867-72.

8. Fletcher M, Leeming J, Cartwright K, Finn A, South West of England Invasive Community Acquired Infection Study G. Childhood empyema: limited potential impact of 7-valent pneumococcal conjugate vaccine. Pediatr Infect Dis J. 2006;25(6):559-60.

9. Gupta R, Crowley S. Increasing paediatric empyema admissions. Thorax. 2006;61(2):179-80.

10. Obando I, Arroyo LA, Sanchez-Tatay D, Moreno D, Hausdorff WP, Brueggemann AB. Molecular typing of pneumococci causing parapneumonic empyema in Spanish children using multilocus sequence typing directly on pleural fluid samples. Pediatr Infect Dis J. 2006;25(10):962-3.

11. Obando I, Arroyo LA, Sanchez-Tatay D, Tarrago D, Moreno D, Hausdorff WP, et al. Molecular epidemiology of paediatric invasive pneumococcal disease in southern Spain after the introduction of heptavalent pneumococcal conjugate vaccine. Clin Microbiol Infect. 2007;13(3):347-8.

12. Roxburgh CS, Youngson GG, Townend JA, Turner SW. Trends in pneumonia and empyema in Scottish children in the past 25 years. Arch Dis Child. 2008;93(4):316-8. 
13. Singleton RJ, Hennessy TW, Bulkow LR, Hammitt LL, Zulz T, Hurlburt DA, et al. Invasive pneumococcal disease caused by nonvaccine serotypes among alaska native children with high levels of 7-valent pneumococcal conjugate vaccine coverage. JAMA. 2007;297(16):1784-92.

14. Spencer DA, Iqbal SM, Hasan A, Hamilton L. Empyema thoracis is still increasing in UK children. BMJ. 2006;332(7553):1333.

15. Eastham KM, Freeman R, Kearns AM, Eltringham G, Clark J, Leeming J, et al. Clinical features, aetiology and outcome of empyema in children in the north east of England. Thorax. 2004;59(6):522-5.

16. Playfor SD, Smyth AR, Stewart RJ. Increase in incidence of childhood empyema. Thorax. 1997;52(10):932.

17. Glenna B, Lossef SV. Purulent pleurisy or empyema. In: Kliegman RM, Stanton BF, Schor NF, St Geme III JW, Behrman RE, editors. Nelson Textbook of Pediatrics. 19 ed. Philadelphia: Saunders; 2011. p. 1507.

18. Atikun Limsukon. Parapneumonic Pleural Effusions and Empyema Thoracis Treatment \& Management. Available from: http:|/emedicine.medscape.com/article/298485-treatment.

19. Menon P, Kanojia RP, Rao KL. Empyema thoracis: Surgical management in children. J Indian Assoc Pediatr Surg. 2009;14(3):85-93.

20. Ulku R, Onat S, Kilic N. Intrapleural fibrinolytic treatment of multiloculated pediatric empyemas. Minerva Pediatr.
2004:56(4):419-23.

21. Doski JJ, Lou D, Hicks BA, Megison SM, Sanchez P, Contidor M, e al. Management of parapneumonic collections in infants and children.J Pediatr Surg. 2000;35(2):265-8.

22. Sonnappa S, Cohen G, Owens CM, van Doorn C, Cairns J, Stanojevic S, et al. Comparison of urokinase and video-assisted thoracoscopic surgery for treatment of childhood empyema. Am J Respir Crit Care Med. 2006;174(2):221-7.

23. Thomson AH, Hull J, Kumar MR, Wallis C, Balfour Lynn IM. Randomised trial of intrapleural urokinase in the treatment of childhood empyema. Thorax. 2002;57(4):343-7.

24. Khan N, Mian I, Javed A, Wazir S, Yousaf M. Efficacy, safety and tolerability of streptokinase in multiloculated empyema. J Ayub Med Coll Abbottabad. 2003;15(4):20-2.

25. Nie W, Liu Y, Ye J, Shi L, Shao F, Ying K, et al. Efficacy of intrapleural instillation of fibrinolytics for treating pleural empyema and parapneumonic effusion: a meta-analysis of randomized control trials. Clin Respir J. 2014;8(3):281-91.

26. Ekingen G, Guvenc BH, Sozubir S, Tuzlaci A, Senel U. Fibrinolytic treatment of complicated pediatric thoracic empyemas with intrapleural streptokinase. Eur J Cardiothorac Surg. 2004;26(3):503-7.

27. Chai FY, Kuan YC. Massive hemothorax following administration of intrapleural streptokinase. Ann Thorac Med. 2011;6(3):149-51. 